\title{
Laboratory study of the effects of flexible vegetation on solute diffusion in unidirectional flow
}

\author{
Sha Lou ${ }^{1,2^{*}} \mathbb{D}$, Hao Wang ${ }^{1}$, Hongzhe Liu' ${ }^{1}$, Guihui Zhong ${ }^{1 *}$, Larisa Dorzhievna Radnaeva ${ }^{3}$, Elena Nikitina ${ }^{3}$,
} Gangfeng $\mathrm{Ma}^{4}$ and Shuguang Liu ${ }^{1,2}$

\begin{abstract}
Background: Flexible vegetation is an important part of the riverine ecosystem, which can reduce flow velocity, change turbulence structure, and affect the processes of solute transport. Compared with the flow with rigid vegetation, which has been reported in many previous studies, bending of flexible vegetation increases the complexity of the flow-vegetation-solute interactions. In this study, laboratory experiments are carried out to investigate the influence of flexible vegetation on solute transport, and methods for estimating the lateral and longitudinal diffusion coefficients in the rigid vegetated flow are examined for their applications to the flow with flexible vegetation.
\end{abstract}

Results: The experimental observations find that vegetation can significantly reduce flow velocity, and the Manning coefficient increases with increasing vegetation density and decreases with inflow discharge. Under all the cases, the vertical peak of the solute concentration moves towards the bottom bed along the flow, and the values of vertical peak concentration longitudinally decreases from the injection point. The lateral diffusion coefficients $D_{y}$ increase with vegetation density, while the longitudinal diffusion coefficients $D_{L}$ are opposite. Both $D_{y}$ and $D_{L}$ increase with the inflow discharge. To estimate the $D_{y}$ and $D_{L}$ in the flow with flexible vegetation, an effective submerged vegetation height considering vegetation bending is incorporated in the methods proposed for flow with rigid vegetation (Lou et al. Environ Sci Eur 32:15, 2020). The modified approach can well predict the diffusion coefficients in the experiments with the relative errors in the range of $5 \%-12 \%$.

Conclusions: The methods proposed in this study can be used to estimate the lateral and longitudinal diffusion coefficients in flows through both rigid and flexible vegetations using the effective submerged vegetation height.

Keywords: Flexible vegetation, Flow velocity, Solute transport, Lateral diffusion coefficient, Longitudinal diffusion coefficient

\section{Background}

Aquatic vegetation, especially flexible vegetation such as reed and bitter grass, is an important part of the river ecosystem. Vegetation can reduce flow velocity, change the turbulence structure, and affect the process of solute transport $[2,5,8,9]$. Interactions between

\footnotetext{
*Correspondence: lousha@tongji.edu.cn; guihui_zhong@tongji.edu.cn

${ }^{1}$ Department of Hydraulic Engineering, Tongji University,

Shanghai 200092, China

Full list of author information is available at the end of the article
}

flow-vegetation-solute are extremely complicated which are affected by vegetation features and hydrodynamic conditions [11]. In flows with flexible vegetation, bending of vegetation is an important factor affecting flow velocity and solute transport, which further increases the difficulty of research on solute transport in flows with flexible vegetation [22].

Solute transport in vegetated flow is affected by the flow structures as well as the vegetation features (density, bending, etc.). Previous studies have discussed solute

\section{Springer Open}

(c) The Author(s) 2021. This article is licensed under a Creative Commons Attribution 4.0 International License, which permits use, sharing, adaptation, distribution and reproduction in any medium or format, as long as you give appropriate credit to the original author(s) and the source, provide a link to the Creative Commons licence, and indicate if changes were made. The images or other third party material in this article are included in the article's Creative Commons licence, unless indicated otherwise in a credit line to the material. If material is not included in the article's Creative Commons licence and your intended use is not permitted by statutory regulation or exceeds the permitted use, you will need to obtain permission directly from the copyright holder. To view a copy of this licence, visit http://creativeco mmons.org/licenses/by/4.0/. 
transport affected by rigid vegetations without bending $[11,12,17,18,23]$. In order to quantitatively study the influence of stem-scale turbulence caused by vegetations on the lateral diffusion of solute transport, Nepf et al. [14] improved the traditional random walk method and introduced a wake coefficient as a key parameter to establish the lateral diffusion model of solute transport affected by emergent vegetation. They proposed a formula for calculating the lateral diffusion coefficient $D_{y}$ which was fitted by the stem-Reynolds number $\left(R_{e d}=u d / v, u\right.$ is the flow velocity, $d$ is the diameter of vegetation, and $v$ is the viscosity coefficient) in the range of 200-1800. Considering the influence of flow velocity on the solute transport, Nepf [16] further investigated solute diffusion processes under different hydrodynamic conditions and improved the formula for estimating $D_{y}$. Based on $[14,16]$, Serra [20] proposed a formula for lateral diffusion coefficient $D_{y}$ affected by vegetation density with solid volume fraction $\phi$ of 0.1-0.35. Based on laboratory tests, Jamali et al. [7] proposed a fitting formula (Jamali's method) for the lateral diffusion coefficient $D_{y}$ of solute affected by submerged vegetations, which took the Reynolds number of vegetation $R_{e d}$ as a key parameter. Jamali's method was easy to use and had high accuracy. However, it was only applicable to the flows with submerged rigid vegetations. Further researches were still needed to determine whether it was appropriate for flexible vegetation.

Nepf et al. [15] carried out laboratory experiments using tracer as solute and extrapolated the longitudinal diffusion coefficient $D_{L}$ of solute transport in flows with rigid vegetation. Influences of wake vortex, wake velocity field and turbulent diffusion on solute transport were investigated by White et al. [26] using theoretical and experimental analysis methods, and a formula of longitudinal diffusion coefficient $D_{L}$ was proposed for solute transport in vegetated flow. Both of the above methods directly described solute transport in rigid vegetated flow, however, the influence of flexible vegetation features on solute transport was not investigated. Hui [6] directly applied the methods of Nepf et al. [14] and Serra [20] to calculate the longitudinal diffusion coefficient $D_{L}$ affected by a flexible vegetation, and modified $D_{L}$ formula including the influence of vegetation-induced drag force coefficient, which showed the accuracy under the Reynolds number of vegetation $R_{e d}$ in the range of 8000-35,000. Based on the experimental tests, Nepf [13] proposed a formula (Nepf's method) of the relationship between $D_{L}$, transport-Reynolds number $\left(R_{e t}\right)$ and vegetation density (i.e., $\phi$ ) under a submerged vegetation. Nepf's method had certain physical significance and accuracy considering the effects of vegetation density on $D_{L}$. However, the application of Nepf's method was limited, because it was proved to be only appropriate for flows affected by rigid submerged vegetation [10], and cannot be used directly to flexible vegetation due to the neglect of vegetation bending.

As the key coefficients of solute transport, descriptions of lateral and longitudinal diffusion coefficients considering both the hydrodynamic conditions and flexible vegetation features (i.e., density and bending) are still lacking, which limits the understanding of solute transport processes with a flexible vegetation canopy. In our previous paper [10], laboratory experiments were carried out to analyze the processes of solute transport affected by rigid vegetations, and modified functions to estimate the lateral and longitudinal diffusions in vegetated flows were proposed under both emergent and submerged vegetation conditions based on previous researches by Nepf [13] and Jamali et al. [7]. This study will focus on the mechanism of solute transport under the influence of a flexible vegetation. In this paper, the effects of a flexible vegetation on the vertical distributions of flow velocity and solute concentration will be investigated. Methods for estimating the lateral and longitudinal diffusion coefficients in the rigid vegetated flow [10] will be examined for their applications to the flows with flexible vegetation, and the improved method of the lateral and longitudinal diffusion coefficients considering both the hydrodynamic conditions and flexible vegetation features will be proposed.

\section{Materials and methods \\ Experimental setup}

Laboratory experiments were conducted in a $2.0-\mathrm{m}$-long and $0.3-\mathrm{m}$-wide rectangle flume, which was made by Plexiglas, at Tongii University, China (Fig. 1a). The current in the flume was driven by an intelligent circulation system, consisting of a pump and stabilizer equipment. Rulers were attached to the side wall of the flume for measuring the bending height of flexible vegetation. Three inflow discharges $(Q=[0.45,0.67,0.9] \mathrm{L} / \mathrm{s})$ were adopted under the constant water depth of $h=0.15 \mathrm{~m}$. Flow velocities were measured by propeller current velocity meters at four sections $\mathrm{S} 1-\mathrm{S} 4(x=[0,10,20,30]$ $\mathrm{cm})$. Each section included 13 vertical monitoring points. The solute discharge system consisted of a peristaltic pump and a backpressure valve. The discharge outlet was placed at the section $x=0$ with a height of $10 \mathrm{~cm}$. Nonadsorptive solute dye tracer carmine was discharged at $10.54 \mathrm{~mL} / \mathrm{s}$ in all tests. Solute concentrations were analyzed at six sections P1-P6 $(x=[0,5,10,15,20,25] \mathrm{cm})$ based on the image processing technology (Fig. 1b). The calibrations of solute concentration in image processing technology and the fitting curve between the solute concentration and image intensity were described by Lou et al. [10]. 


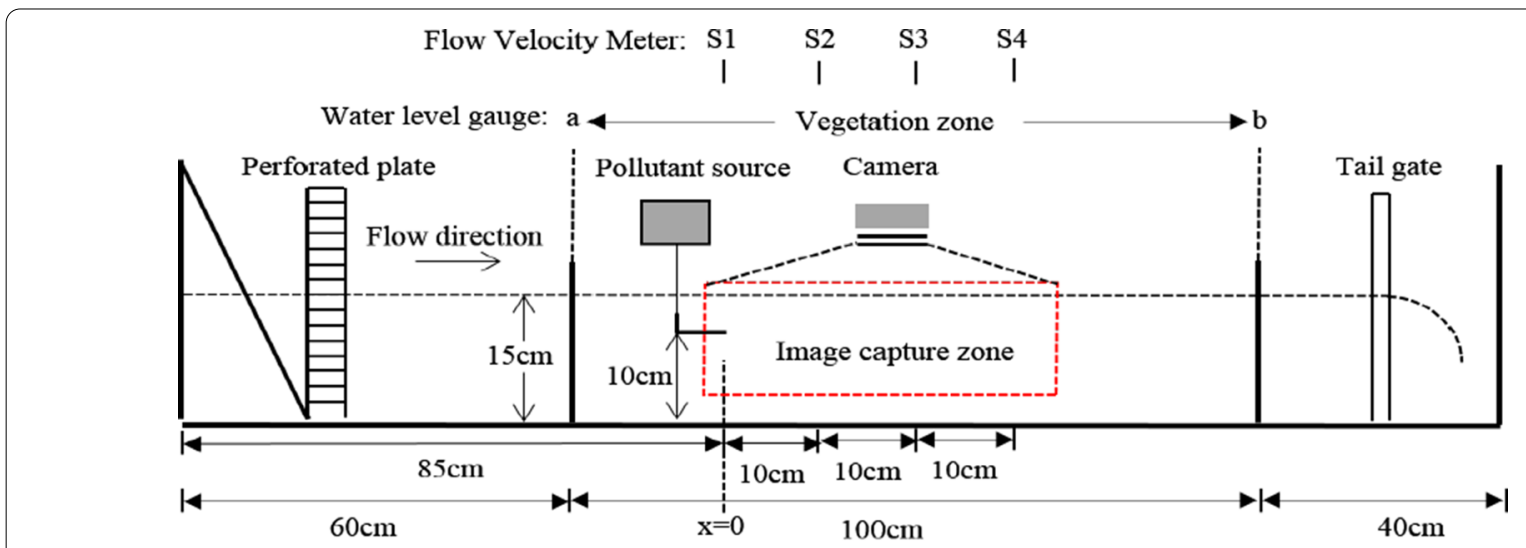

(a) Front view

Pollutant monitoring section: P1 P2 P3 P4 P5 P6

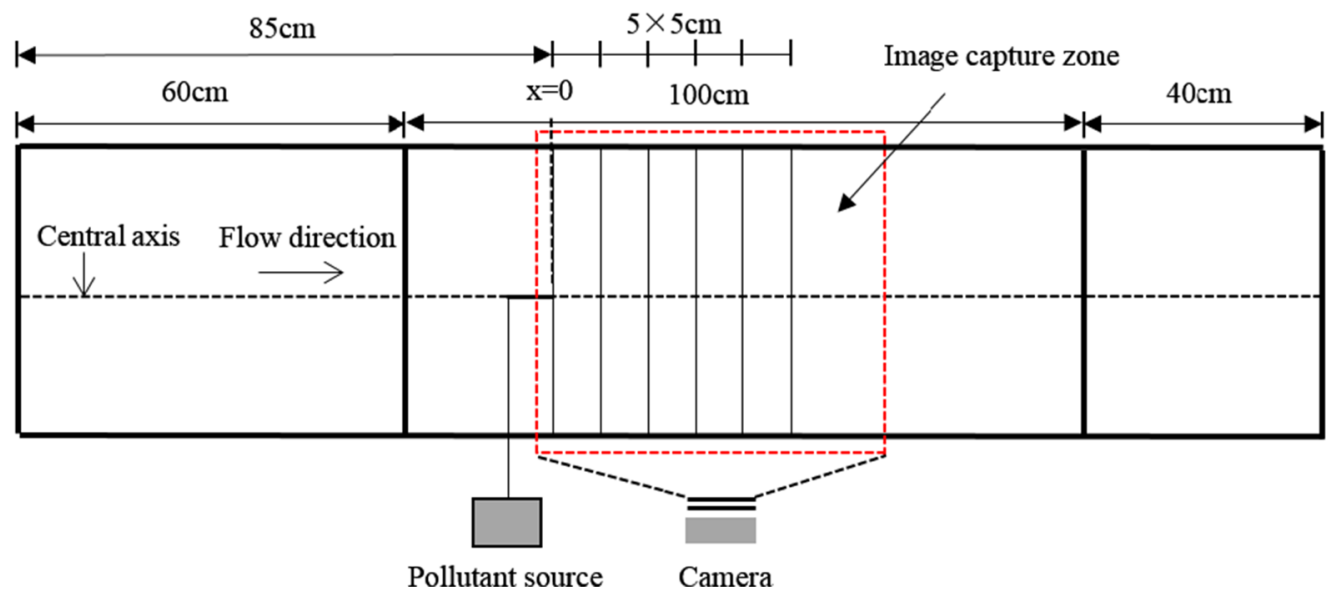

(b) Left view

Fig. 1 Schematic of the current circulation system

Table 1 Flexible vegetation conditions

\begin{tabular}{llll}
\hline Case & $\begin{array}{l}\text { Density } \boldsymbol{N} \\
\left(\mathbf{s t e m s} / \mathbf{m}^{\mathbf{2}}\right)\end{array}$ & $\begin{array}{l}\text { Solid volume } \\
\text { fraction } \boldsymbol{\varphi}\end{array}$ & Arrangements \\
\hline AA & 316.7 & 0.016 & Rectangular distribution \\
AB & 158.4 & 0.008 & Rectangular distribution \\
AC & 158.4 & 0.008 & Staggered distribution \\
\hline
\end{tabular}

The mimic flexible vegetation made by plastic optical fiber and Plexiglas tube was used in the experiments. The vegetation was placed in holes drilled in the false bottom of the flume. The vegetation zone was $1.0 \mathrm{~m}$ long and located in the middle of the flume. The height of vegetation $\left(h_{v}\right)$ was $0.27 \mathrm{~m}$ including $0.05 \mathrm{~m}$ Plexiglas tube in the bottom, and the diameter $(d)$ was $0.006 \mathrm{~m}$. Vegetation configurations are shown in Table 1: Case AA, dense vegetation in a rectangular distribution; Case $A B$, sparse vegetation in a rectangular distribution; Case $\mathrm{AC}$, sparse vegetation in a staggered distribution. The vegetation arrangements are shown in Fig. 2.

\section{Formulae of the lateral and longitudinal diffusion coefficients}

The double station linear analytical method was commonly adopted in the tracer experiments to calculate the lateral and longitudinal diffusion coefficients [24, 29], given in Eqs. (1) and (2):

$$
c(x, y, t)=\frac{C q}{h u \sqrt{4 \pi D_{y} x / \bar{u}}} \exp \left[-\frac{\bar{u} y^{2}}{4 D_{y} x}\right],
$$




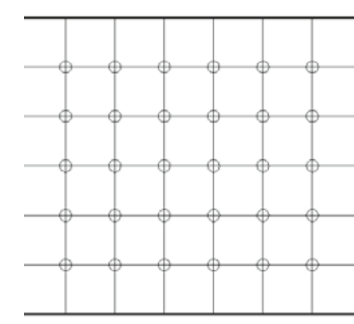

(a) Case AA

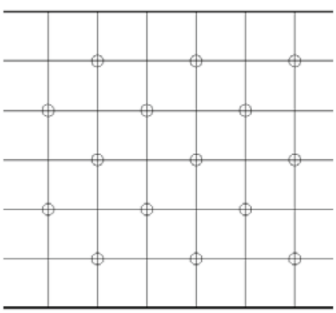

(c) Case AC

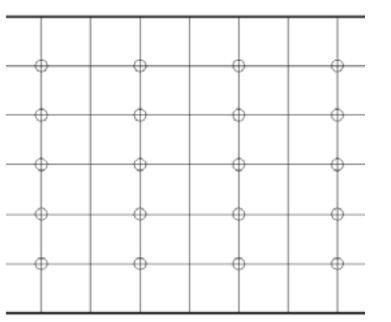

(b) Case AB

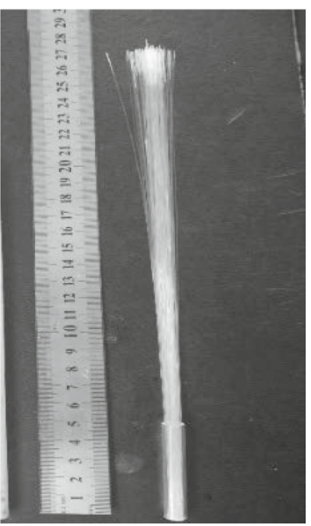

(d) Mimic flexcible vegetation
Fig. 2 Vegetation arrangements

$$
c(x, t)=\frac{W}{A \sqrt{4 D_{L} \pi t}} \exp \left[-\frac{(x-\bar{u} t)^{2}}{4 D_{L} t}\right],
$$

where $x$ is the longitudinal direction and $y$ is the transverse direction; $h$ is the water depth $(\mathrm{cm}) ; \bar{u}$ is the average flow velocity of the section $(\mathrm{cm} / \mathrm{s}) ; q$ is the solute inflow velocity $(\mathrm{mL} / \mathrm{s}) ; W$ is the mass of the release solute $(\mathrm{mg})$; $A$ is the cross-sectional area $\left(\mathrm{cm}^{2}\right) ; D_{y}$ and $D_{L}$ are the lateral and longitudinal diffusion coefficients $\left(\mathrm{cm}^{2} / \mathrm{s}\right) ; k$ is the first-order reaction rate of the solute $\left(\mathrm{s}^{-1}\right) ; C(x, t)$ is the solute concentration $(\mathrm{mg} / \mathrm{L})$ at the downstream station with distance $x(\mathrm{~cm})$ from the injection outlet at time $t(\min ) ; C(x, y)$ is the solute concentration $(\mathrm{mg} / \mathrm{L})$ at position $(x, y)$; and $C_{0}$ is the initial concentration $(\mathrm{mg} / \mathrm{L})$.

In flows with vegetation, the canopy and stem-scale turbulences induced by vegetation increase the turbulence intensity and the Reynolds stresses, which enhance the mixing and diffusion of solute $[9,28]$. On the other hand, the flow velocity is reduced because of the physical obstruction of the vegetation, resulting in the decreasing of solute diffusion. The solute transport in vegetated flow mainly depends on the combined effects of these two processes.

\section{Lateral diffusion coefficient of solute transport in vegetated flow}

Based on laboratory investigations, Jamali et al. [7] proposed a fitting equation for the lateral diffusion coefficient of solute transport in flows with emergent rigid vegetations using the stem-Reynolds number $\left(R e_{d}\right)$ as the key parameter (Jamali's method), written as:

$$
\frac{D_{y}}{u d}=a+b \operatorname{Re}_{d}^{-2(1-\phi)},
$$

where $a$ and $b$ are parameters which were determined to be 0.18 and 2157 when $\phi<0.015$, and 0.175 and 1035 when $\phi>0.015$, respectively. Jamali's method was simple for flows with emergent vegetations, however, it is only applicable to the condition that rigid vegetation is completely emergent and its density is vertically uniform.

To estimate the lateral diffusion coefficient in flows with submerged vegetation, Jamali's method (Eq. 3) was improved by Lou et al. [10] based on laboratory observations, which are shown in Eq. (4). New parameters $a^{\prime}$ and $b^{\prime}$ were related to the relative water depth (i.e., the ratio of vegetation height to water depth) (Eqs. 5 and 6):

$$
\begin{aligned}
& \frac{D_{y}}{u d}=a^{\prime}+b^{\prime} R e_{d}^{-2(1-\phi),} \\
& a^{\prime}=-4.95\left(\frac{h_{v}^{\prime}}{h}\right)^{2}+6.75 \frac{h_{v}^{\prime}}{h}+0.2, \\
& b^{\prime}=2137.5\left(\frac{h_{v}^{\prime}}{h}\right)^{2}-2737.5 \frac{h_{v}^{\prime}}{h}+75,
\end{aligned}
$$

where $h$ is water depth, $h_{v}{ }^{\prime}$ is the submerged vegetation height $\left(h_{v}{ }^{\prime}=h\right.$ in case with emergent vegetation), and $h_{v}{ }^{\prime} / h$ is the relative water depth (the ratio of vegetation height to water depth).

\section{Longitudinal diffusion coefficient of solute transport in vegetated flow}

Nepf [13] proposed a formula to estimate longitudinal diffusion coefficient of solute transport in flows with emergent rigid vegetation which is given in Eq. (7). Her method related the longitudinal diffusion coefficient to the transport-Reynolds number $\left(R_{e t}\right)$ and vegetation features (i.e., solid volume fraction, vegetation diameter, and vegetation-induced drag coefficient):

$$
\frac{D_{L}}{u d}=\sqrt{\frac{C_{D}^{3} R_{e t}}{128}}+\frac{C_{D} \phi}{\pi(1-\phi)}+\gamma u \tau \frac{4 \phi}{\pi d},
$$


in which $R_{e t}$ is the transport-Reynolds number under the lateral wake spreading, and $R_{e t}=u d /\left(v+v_{t}\right)$ is constant across a wide range of Reynolds numbers for turbulent wakes when the turbulent viscosity $\left(v_{t}\right)$ is larger than the molecular viscosity $(v)$; $v_{t}$ is determined as $0.03 \mathrm{~cm}^{2} / \mathrm{s}$ according to Nepf [13], $C_{D}$ is the vegetationinduced drag coefficient which is calculated by stemReynolds numbers $R_{e d}$ with $C_{D}=1+10 \times R_{e d}{ }^{-2 / 3}$ [25]; $\gamma$ is a function of stem-Reynolds numbers $R_{e d}$ and the length scale of the recirculation zone behind the vegetation $\gamma d[4] ; \tau$ is the resident time of the solute with $\tau=d^{2} / 4 D$ and a diffusion constant $D$.

Lou et al. [10] improved Nepf's method (Eq. 7) by introducing a relative water depth $\left(h_{v}{ }^{\prime} / h\right)$ to describe the submergence of rigid vegetation, which are given by

$$
\frac{D_{L}}{u d}=\left(\sqrt{\frac{C_{D}^{3} R_{e t}}{128}}+\frac{C_{D B} \phi}{\pi(1-\phi)}+\gamma u \tau \frac{4 \phi}{\pi d}\right) \times\left(\frac{h_{v}^{\prime}}{h}\right)^{-0.75} .
$$

Equations (4) and (8) were proved to be acceptably accurate for estimation of lateral and longitudinal diffusion coefficients of solute transport in flows with submerged rigid vegetation [10]. The methods can also be used for solute transport within emergent rigid vegetations with the relative water depth $\left(h_{v}^{\prime} / h\right)$ as 1.0. However, in flows with flexible vegetation, flow velocity and solute transport are affected by the bending of vegetation, which should be accounted for somehow in the prediction equations.

\section{Results \\ Vertical distribution of mean velocity affected by flexible vegetation}

Vertical distributions of mean velocities in Case AA, Case $\mathrm{AB}$ and Case $\mathrm{AC}$ are shown in Fig. 3. Affected by flexible vegetation, the mean velocity was reduced significantly in the vegetation region. The $u$ in Case AA with a higher vegetation density was slightly smaller than that in Cases $A B$ and $A C$. Similar vertical profiles of mean velocities were found in Case $A B$ and Case $A C$, indicating that vegetation arrangements (rectangular and staggered distributions) had less influence on mean velocities in the present experiments. Comparing the results in Cases $\mathrm{AA}$ and $\mathrm{AB}$ with those affected by rigid vegetation at $x=20 \mathrm{~cm}$ (Case E and Case F in [10]), it was found that the flexible vegetation resulted in smaller mean velocities than rigid vegetation with the same vegetation density. The visible bending of flexible vegetation greatly reduced the flow energy, causing more severe decrease in velocities.
Vertically averaged velocities at sections S1-S4 are compared in Fig. 4 to discuss the longitudinal distribution of velocities affected by flexible vegetation. It was indicated that the vertically averaged velocities in Case AA were much lower $(4.3 \%-8.5 \%)$ than those in Cases $\mathrm{AB}$ and $\mathrm{AC}$ under higher inflow discharge conditions (i.e., $Q=0.67$ and $0.9 \mathrm{~L} / \mathrm{s}$ ). Under the inflow of $0.9 \mathrm{~L} / \mathrm{s}$, reductions of the vertically averaged velocities from S1 to S4 were $16.7 \%$ in Cases AA, and $10 \%$ in Cases $\mathrm{AB}$ and $A C$. In Case $A B$ and Case $A C$ with rectangular and staggered distributions, respectively, the longitudinal distributions of the vertically averaged velocities almost coincided with the difference of only $0.3 \%-2.2 \%$. The vegetation arrangement may change the path of flow, but the averaged velocities were relatively close due to the similar vegetation resistance caused by vegetation with the same density.

To estimate the resistance of flexible vegetation on flow, the Manning coefficient $(n)$ was calculated by $n=\frac{1}{u} R^{\frac{2}{3}} J^{\frac{1}{2}}$ ( $R$ : the hydraulic radius; $J$ : hydraulic gradient) [1, 3, 27]. Comparisons of Manning coefficients in Case AA, AB and $\mathrm{AC}$ are shown in Fig. 5. The Manning coefficients in Case AA with denser vegetation were the highest under all the inflow discharge conditions comparing with those in Cases $A B$ and $A C$, resulting in the lower mean velocities in Case AA. The Manning coefficients decreased with the increasing inflow discharge in all cases. In Case AA, the Manning coefficients were in the range of $0.15-$ 0.20 under $Q=0.45 \mathrm{~L} / \mathrm{s}$, while they were $0.14-0.18$ under $Q=0.67 \mathrm{~L} / \mathrm{s}$ and $0.12-0.15$ under $Q=0.90 \mathrm{~L} / \mathrm{s}$. With different vegetation arrangements, the Manning coefficients were almost the same as found in Cases $A B$ and $A C$, indicating again that the vegetation density had more influence on flow velocities than vegetation arrangement.

\section{Distribution of solute concentrations affected by flexible vegetation}

The vertical profiles of the time-averaged solute concentrations $(C)$ at sections P1-P6 normalized by the max concentration at $x=0 \mathrm{~cm}\left(C_{\max }=1000 \mathrm{mg} / \mathrm{L}\right)$ are displayed in Fig. 6. The data were obtained from the average values of 150 frames which were continually collected $5 \mathrm{~s}$ after the release of the solute. The vertical peaks of solute concentrations moved towards the bottom bed from section P1 $(x=0 \mathrm{~cm})$ to P6 $(x=25 \mathrm{~cm})$ caused by the gravity, and the values of vertical peak longitudinally decreased. Comparing the results in Case AA and $\mathrm{AB}$, the solute concentration was relatively lower in the case with denser vegetation. In Case AA, denser vegetation reduced the flow velocity and impeded the diffusion of solute. Both the positions and values of vertical peaks were close affected by the rectangular and staggered vegetation in Cases $\mathrm{AB}$ and $\mathrm{AC}$. The vertical peaks of solute 


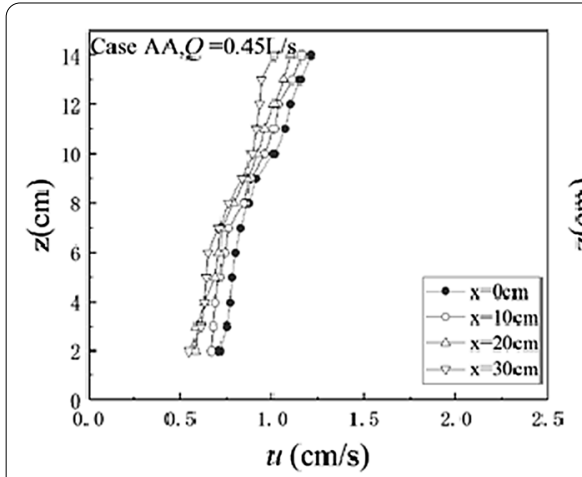

(a) Case AA \& $Q=0.45 \mathrm{~L} / \mathrm{s}$

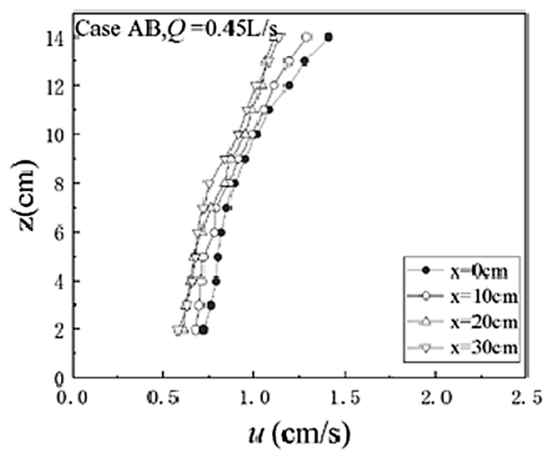

(d) Case AB \& $Q=0.45 \mathrm{~L} / \mathrm{s}$

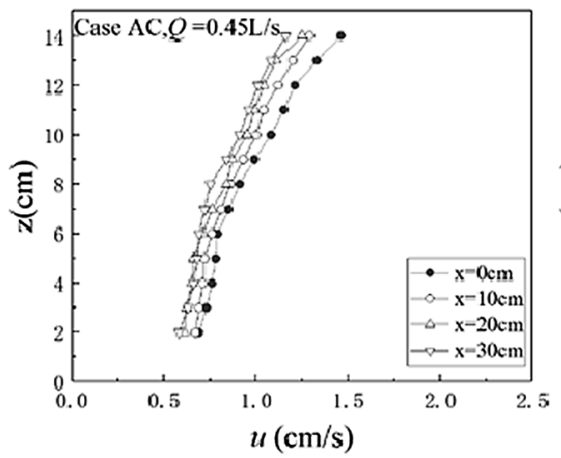

(g) Case AC \& $Q=0.45 \mathrm{~L} / \mathrm{s}$

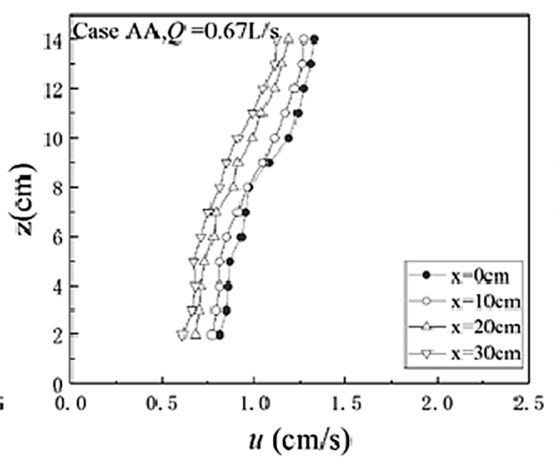

(b) Case AA \& $Q=0.67 \mathrm{~L} / \mathrm{s}$

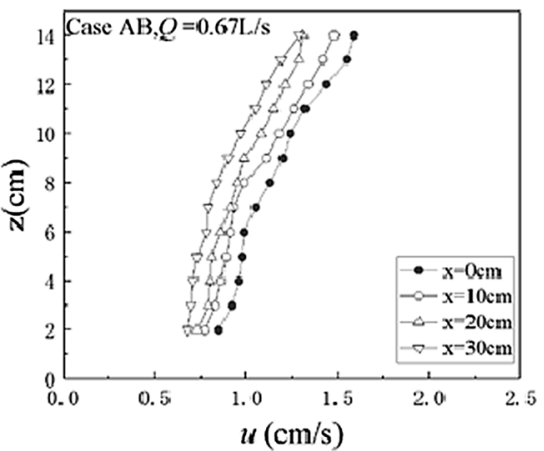

(e) Case $\mathrm{AB} \& Q=0.67 \mathrm{~L} / \mathrm{s}$

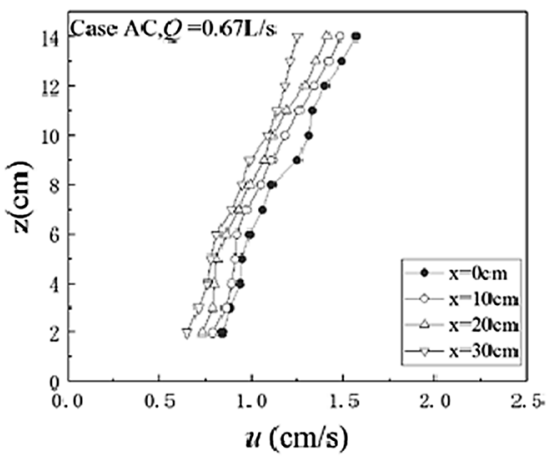

(h) Case AC \& $Q=0.67 \mathrm{~L} / \mathrm{s}$

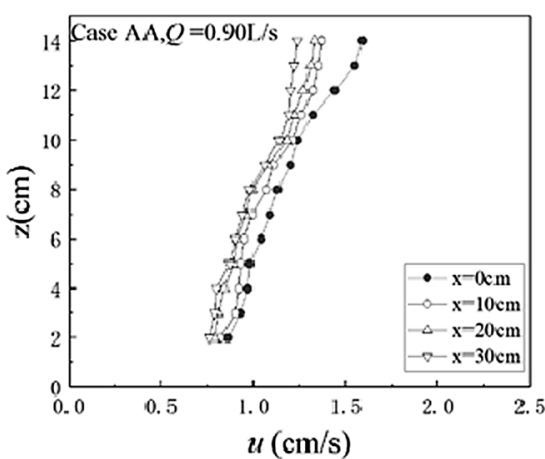

(c) Case AA \& $Q=0.90 \mathrm{~L} / \mathrm{s}$

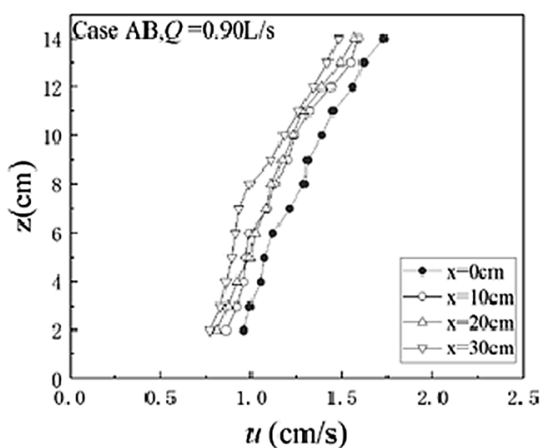

(f) Case $\mathrm{AB} \& Q=0.90 \mathrm{~L} / \mathrm{s}$

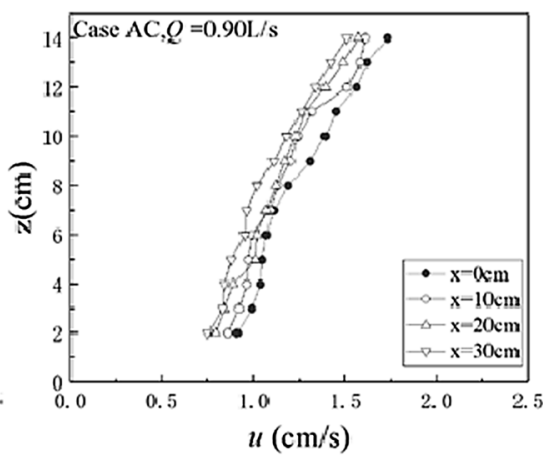

(i) Case AC \& $Q=0.90 \mathrm{~L} / \mathrm{s}$

Fig. 3 Vertical profiles of mean velocities at sections $S 1(x=0 \mathrm{~cm})-S 4(x=30 \mathrm{~cm})$

concentrations at section of $x=20 \mathrm{~cm}$ appeared around $z / h=0.4$ in the cases affected by rigid vegetation (Case $E$ and Case $F$ in [10]), which were found to be around $z / h=0.6$ with the flexible vegetation. In both two series of tests with the rigid and flexible vegetation, the solute discharge outlet was placed at section $x=0$ with a height of $10 \mathrm{~cm}(z / h=0.67)$, and the locations of vertical solute concentration peaks moved downward at the section of $x=20 \mathrm{~cm}$ due to the diffusion process and the gravity effect. In flows with flexible vegetation, the movement of flexible vegetation affected the vertical distributions of turbulence development and the solute concentration.

The variation coefficient $(\delta)$ of solute concentration in the cross-section, calculated by $\delta=\sqrt{\sum_{i=1}^{n}\left(C_{i}-\bar{C}\right)^{2}} / \bar{C}$ $\left(C_{i}\right.$ : concentration of solute at position $(i) ; \bar{C}$ : the average concentration of solute in the section) $[19,21]$, was applied to analyze the vertical distribution of solute concentration. The value of $\delta$ decreased with stronger 


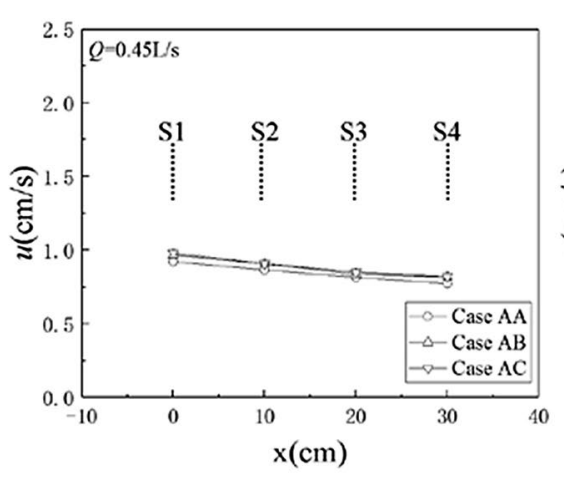

(a) $Q=0.45 \mathrm{I} / \mathrm{s}$

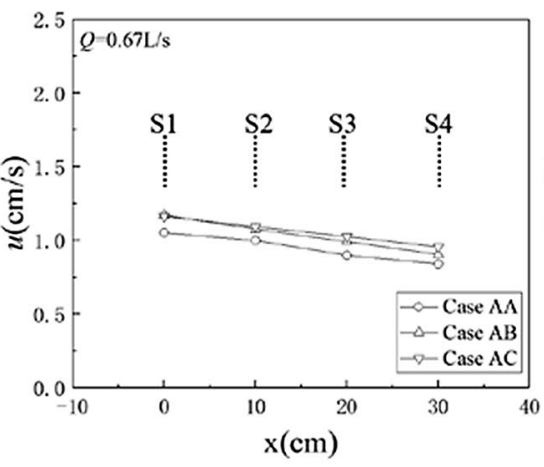

(b) $Q=0.67 \mathrm{~L} / \mathrm{s}$

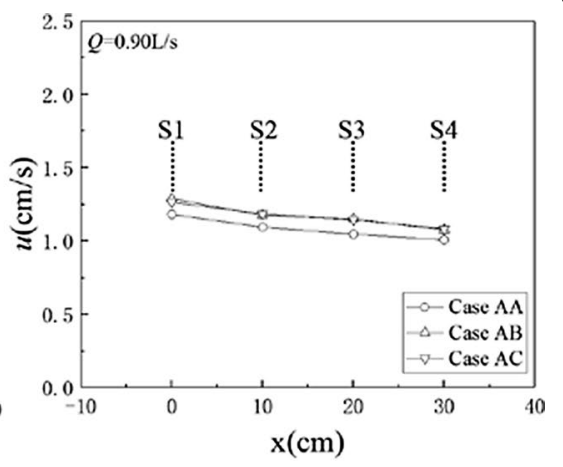

(c) $Q=0.90 \mathrm{~L} / \mathrm{s}$

Fig. 4 Comparison of vertically averaged velocities at sections S1-S4

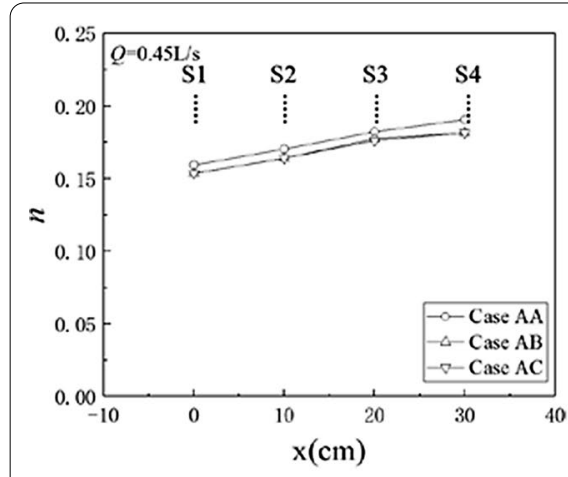

(a) $Q=0.45 \mathrm{I} / \mathrm{s}$

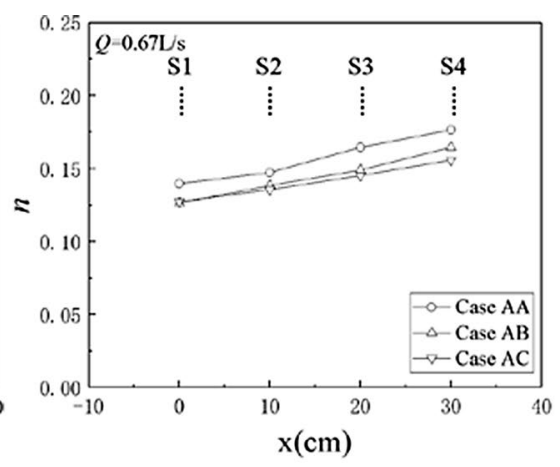

(b) $Q=0.67 \mathrm{~L} / \mathrm{s}$

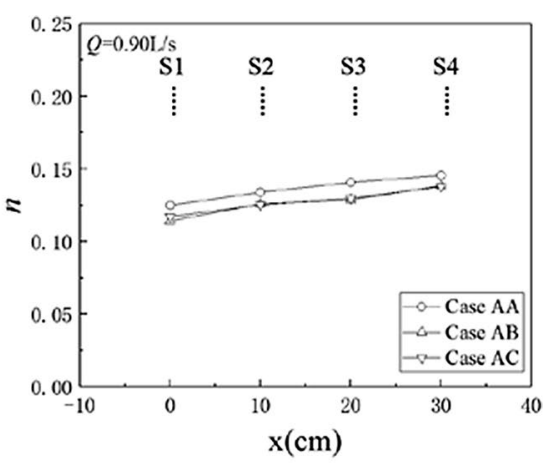

(c) $Q=0.90 \mathrm{~L} / \mathrm{s}$

Fig. 5 Comparisons of Manning coefficients $n$ at sections S1-S4

vertical mixing. The values of $\delta$ at sections P1-P6 are shown in Table 2. The values of $\delta$ at section P6 were much smaller than those at section P1, indicating the decreasing of $\delta$ and increasing vertical mixing along the flow direction within the vegetation zone. The values of $\delta$ in Case AA with a dense vegetation canopy were generally higher than those in Case $\mathrm{AB}$ with a sparse vegetation canopy. The values of $\delta$ in Case $\mathrm{AB}$ and Case AC were close due to the same vegetation density. Although the denser vegetation generated higher stem-scale turbulence within the vegetation zone, the vertical distribution of stem-scale turbulence for emergent vegetation was quite uniform from the surface to the bottom. The mean flow velocity was also lower in case with a dense vegetation than that with a sparse vegetation. The smaller velocity in Case AA led to weak flow turbulence and vertical mixing, resulting in higher $\delta$ values.

\section{Lateral and longitudinal diffusion coefficients by the double station linear analytical method}

The lateral $\left(D_{y}\right)$ and longitudinal $\left(D_{L}\right)$ diffusion coefficients were calculated using Eqs. (1) and (2). Vegetation density had an opposite impact on $D_{y}$ and $D_{L}$. The values of $D_{y}$ in Case AA were relatively larger than those in Case $A B$, indicating that higher vegetation density enhanced the lateral diffusion of solute. The dense vegetation in Case AA produced strong stem-scale turbulence which increased the vertical mixing of solute. Conversely, the values of $D_{L}$ in Cases AA were smaller than those in Case $A B$. Due to the higher vegetation resistance, flow velocity affected by a denser vegetation in Case AA was lower than that in Case $A B$, which decreased the longitudinal diffusion of solute. According to the present results, the lateral diffusion of solute was mainly determined by the turbulence intensity, while the longitudinal diffusion depended on the flow velocity in the vegetated flow. $D_{y}$ and $D_{L}$ in Cases $\mathrm{AB}$ were generally close to those in Case AC. The vegetation arrangement might change the flow path, but had minor effects on the mean velocity and solute concentration, resulting in similar values of diffusion coefficients in Cases $\mathrm{AB}$ and $\mathrm{AC}$.

As shown in Table 3, both $D_{y}$ and $D_{L}$ increased with the inflow discharge. The relationship between lateral and longitudinal diffusion coefficients and the stem-Reynolds 

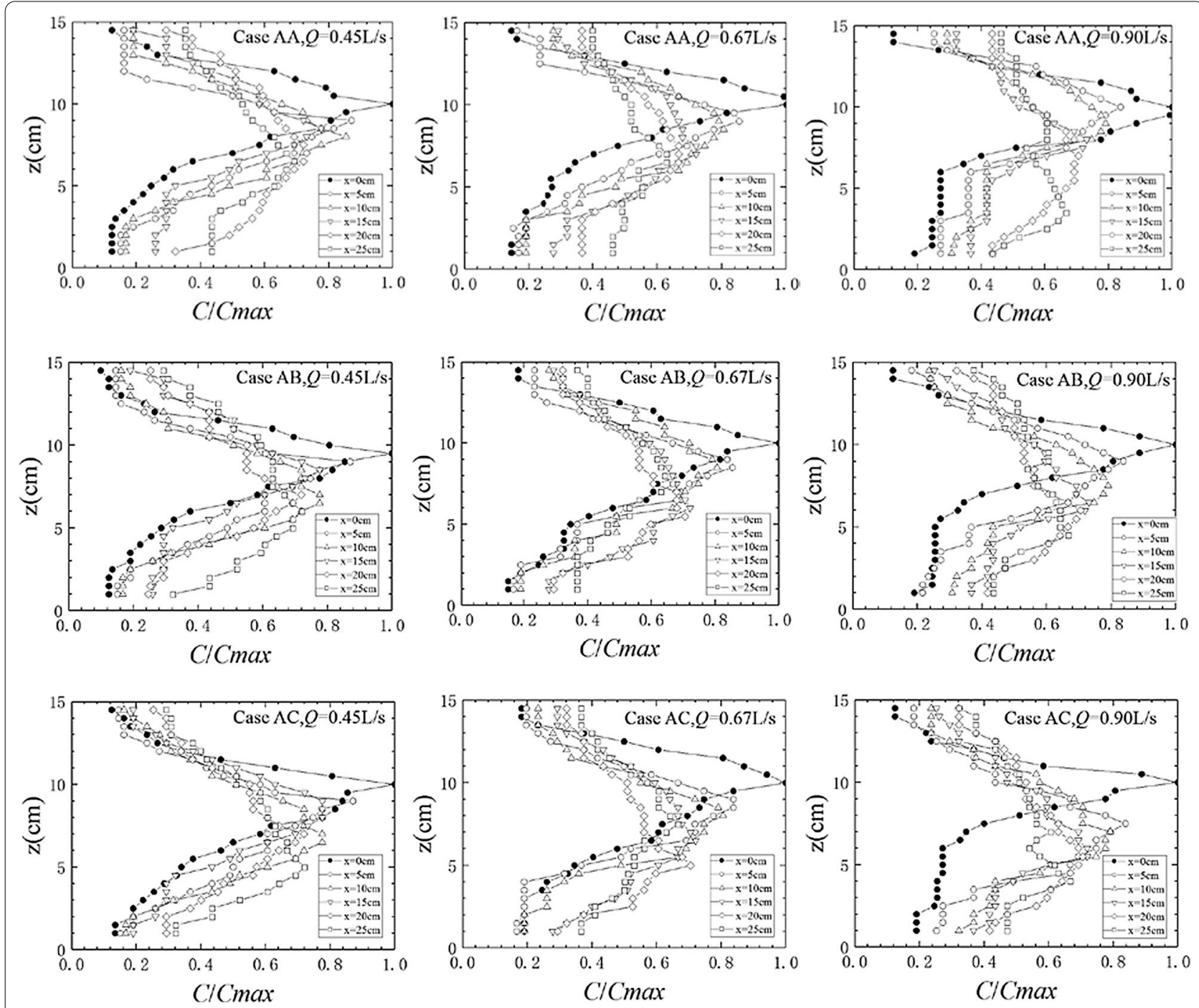

Fig. 6 Vertical profiles of solute concentrations at sections P1 $(x=0 \mathrm{~cm})-P 6(x=25 \mathrm{~cm})$

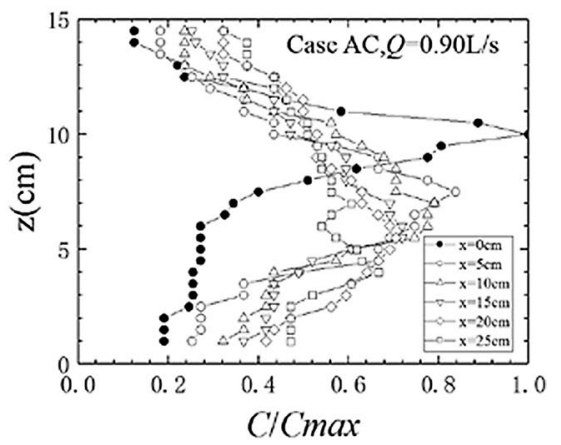

Table 2 Variation coefficients of solute concentration at sections P1-P6

\begin{tabular}{|c|c|c|c|c|c|c|c|}
\hline Cases & & P1 & P2 & P3 & P4 & P5 & P6 \\
\hline \multirow[t]{3}{*}{ AA } & $Q=0.45 \mathrm{~L} / \mathrm{s}$ & 0.655 & 0.622 & 0.529 & 0.433 & 0.385 & 0.314 \\
\hline & $Q=0.67 \mathrm{~L} / \mathrm{s}$ & 0.862 & 0.700 & 0.512 & 0.449 & 0.303 & 0.317 \\
\hline & $Q=0.90 \mathrm{~L} / \mathrm{s}$ & 0.611 & 0.554 & 0.518 & 0.377 & 0.320 & 0.258 \\
\hline \multirow[t]{3}{*}{$A B$} & $Q=0.45 \mathrm{~L} / \mathrm{s}$ & 0.739 & 0.548 & 0.366 & 0.274 & 0.219 & 0.167 \\
\hline & $Q=0.67 \mathrm{~L} / \mathrm{s}$ & 0.610 & 0.429 & 0.322 & 0.306 & 0.234 & 0.106 \\
\hline & $Q=0.90 \mathrm{~L} / \mathrm{s}$ & 0.594 & 0.389 & 0.341 & 0.240 & 0.249 & 0.138 \\
\hline \multirow[t]{3}{*}{$A C$} & $Q=0.45 \mathrm{~L} / \mathrm{s}$ & 0.652 & 0.458 & 0.388 & 0.233 & 0.172 & 0.191 \\
\hline & $Q=0.67 \mathrm{~L} / \mathrm{s}$ & 0.606 & 0.451 & 0.428 & 0.307 & 0.280 & 0.207 \\
\hline & $Q=0.90 \mathrm{~L} / \mathrm{s}$ & 0.679 & 0.482 & 0.419 & 0.340 & 0.300 & 0.213 \\
\hline
\end{tabular}


Table 3 The lateral $\left(D_{y}\right)$ and longitudinal $\left(D_{L}\right)$ diffusion coefficients

\begin{tabular}{|c|c|c|c|c|c|c|}
\hline \multirow[t]{2}{*}{ Case } & \multicolumn{3}{|l|}{$D_{y}\left(\mathrm{~cm}^{2} / \mathrm{s}\right)$} & \multicolumn{3}{|l|}{$D_{L}\left(\mathrm{~cm}^{2} / \mathrm{s}\right)$} \\
\hline & $Q=0.45 \mathrm{~L} / \mathrm{s}$ & $Q=0.67 \mathrm{~L} / \mathrm{s}$ & $Q=0.90 \mathrm{~L} / \mathrm{s}$ & $Q=0.45 \mathrm{~L} / \mathrm{s}$ & $Q=0.67 \mathrm{~L} / \mathrm{s}$ & $Q=0.90 \mathrm{~L} / \mathrm{s}$ \\
\hline AA & 1.44 & 2.18 & 2.62 & 46.75 & 57.31 & 74.61 \\
\hline$A B$ & 1.37 & 2.07 & 2.45 & 59.70 & 65.02 & 83.26 \\
\hline$A C$ & 1.32 & 1.96 & 2.32 & 62.96 & 66.99 & 81.53 \\
\hline
\end{tabular}

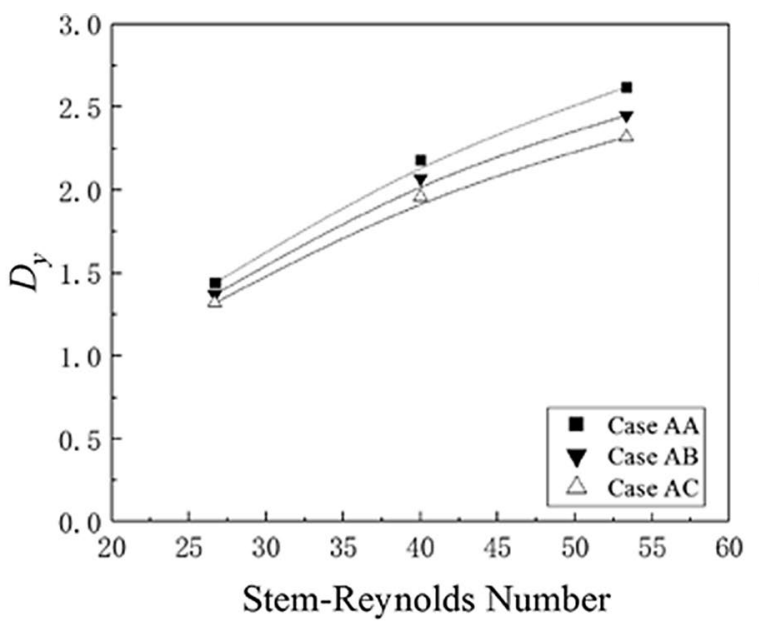

(a) $D_{y} \sim R_{e d}$

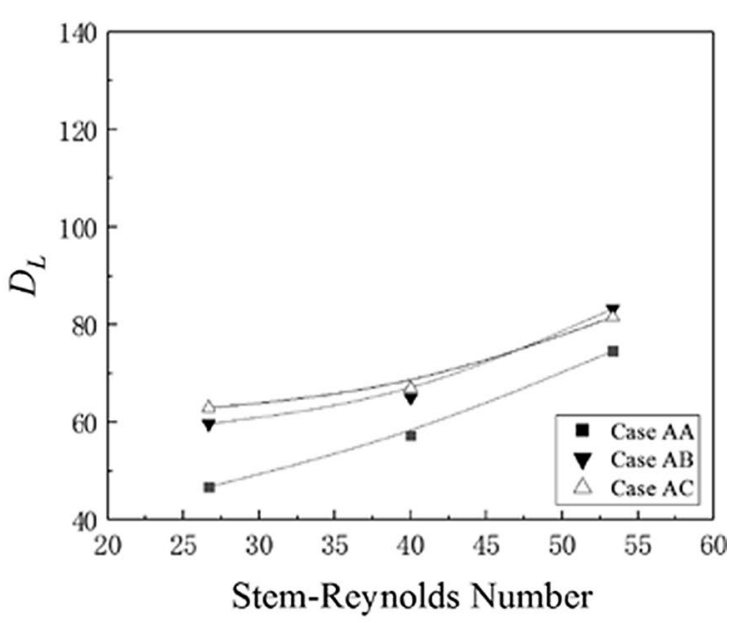

(b) $D_{L} \sim R_{e d}$

Fig. 7 Relationships between lateral $D_{y}$ and longitudinal $D_{L}$ diffusion coefficients and $R_{e d}$

number $R_{e d}$ is shown in Fig. 7. Both $D_{y}$ and $D_{L}$ were proportional to $R_{e d}$. Under a larger inflow discharge, flow velocity increased in the vegetation zone, which directly enhanced the longitudinal diffusion of solute. With a larger velocity, the oscillation and turbulence also increased in the vegetation zone, resulting in stronger vertical mixing of solute and more intense lateral diffusion of solute.

\section{Discussion}

\section{Influence of flexible vegetation bending on lateral diffusion coefficient $D_{y}$}

The comparisons of experimental (points, Table 3) and predicted (lines, Eqs. 4-6) values of $D_{y}$ versus $R_{e d}$ are displayed in Fig. 8. Noticeable deviations could be found between the scattered points and the lines, with the relative errors of $139.7 \%, 59.7 \%$ and $54.5 \%$ in Cases $\mathrm{AA}, \mathrm{AB}$ and $\mathrm{AC}$, respectively. According to the experimental results, the values of $D_{y} /(u \cdot d)$ were proportional to $R_{e d}$ in both the dense (Case AA) and sparse (Case $\mathrm{AB}$ and Case $\mathrm{AC}$ ) cases, which was consistent with the positive relationship between $D_{y}$ (as well as $D_{L}$ ) and $R_{e d}$ in Fig. 7. With the growing $u, D_{y}$ increased even more, resulting in larger $D_{y} /(u \cdot d)$. However, opposite trends appeared in the predicted results directly using Eqs. (4-6), showing the negative relationship between $D_{y} /(u \cdot d)$ and $R_{e d}$. Equations (4-6) were developed to estimate the lateral diffusion coefficient affected by a rigid vegetation [10], which was proved to be not appropriate for flows with a flexible vegetation.

The main difference between rigid and flexible vegetation in the unidirectional flow was the bending and the effective vegetation height. In Eqs. (4-6), a relative water depth $h_{v}{ }^{\prime} / h$ was introduced to describe the effective vegetation height in the water column. The degree of bending of flexible vegetation varied with hydrodynamic conditions. In the present experiments, the effective submerged vegetation height was in the range of $11 \mathrm{~cm}-15 \mathrm{~cm}$. Using the averaged value of effective submerged vegetation height $h_{v}{ }^{\prime \prime}=12 \mathrm{~cm}, a^{\prime}=2.43$ and $b^{\prime}=747$ were obtained by Eqs. (5-6). Substituting the newly determined $a^{\prime}$ and $b^{\prime}$ into Eq. (4), a modified formula to calculate the solute lateral diffusion coefficient in flows with flexible vegetation was written as:

$$
\frac{D_{y}}{u d}=2.43-747 R e_{d}^{-2(1-\phi)} .
$$

Figure 9 shows the correlations between the experimental (points, Table 3) and improved predicted (lines, 

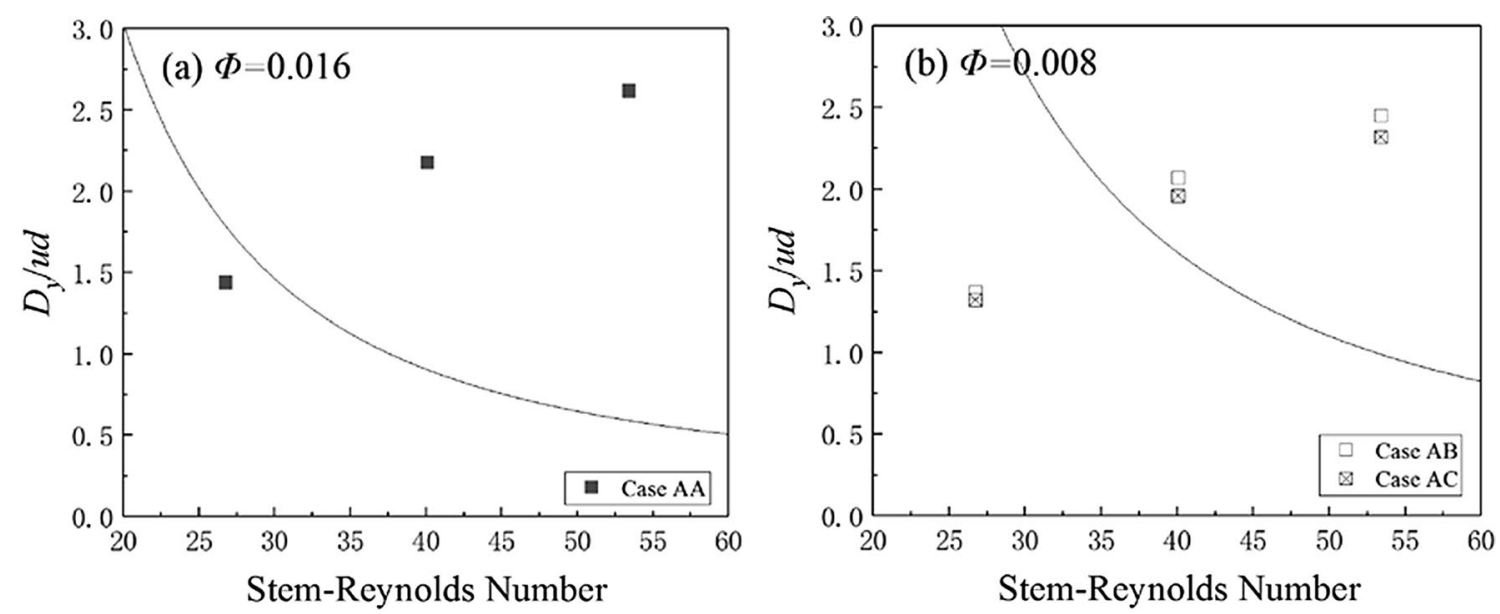

Fig. 8 Comparisons of the experimental (points, Table 3) and predicted (lines, Eqs. 4-6) values of $D_{y}$ versus $R_{e d}$

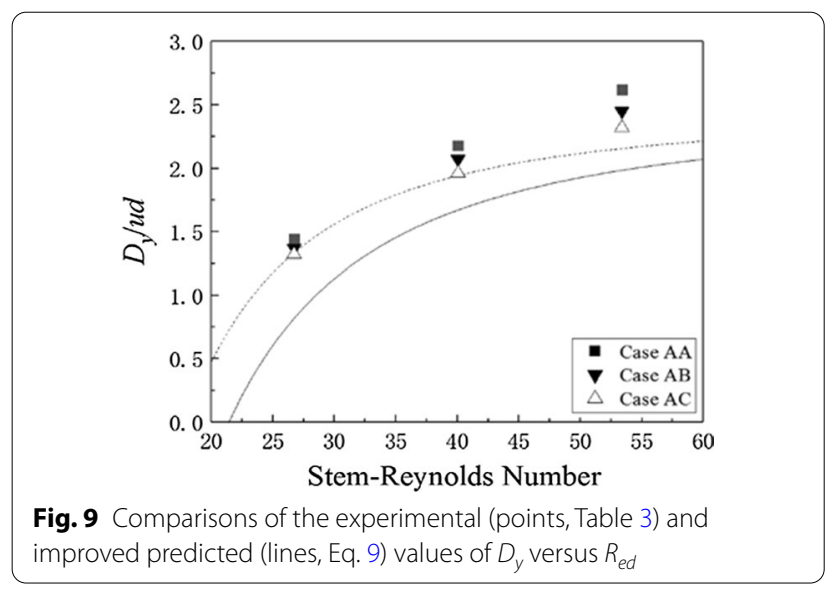

Eq. 9) $D_{y}$ and $R_{e d}$. The deviations between the experimental data and improved predictions were obviously reduced with the relative errors of $11.2 \%, 6.4 \%$ and $6.6 \%$ in Case $\mathrm{AA}, \mathrm{AB}$, and $\mathrm{AC}$. By using the effective vegetation height $h_{v}{ }^{\prime \prime}$ instead of $h_{v}{ }^{\prime}$, Eq. 9 can reasonably describe the positive correlations between $D_{y} /(u \cdot d)$ and $R_{e d}$. It was indicated that the bending of the flexible vegetation (i.e., the effective vegetation height) had a great influence on the lateral diffusion of solute transport under a unidirectional flow.

\section{Influence of flexible vegetation bending on longitudinal diffusion coefficient $D_{L}$}

To discuss the influence of flexible vegetation bending on longitudinal diffusion coefficient $D_{L}$, the experimental $D_{L}$ in Table 3 (Exp. points) were compared with the predicted results by Eq. (8) (Pre. points and lines) in Fig. 10. Equation (8) underpredicted the experimental $D_{L}$ with the relative errors of $14.2 \%, 29.7 \%$ and $28.4 \%$ in

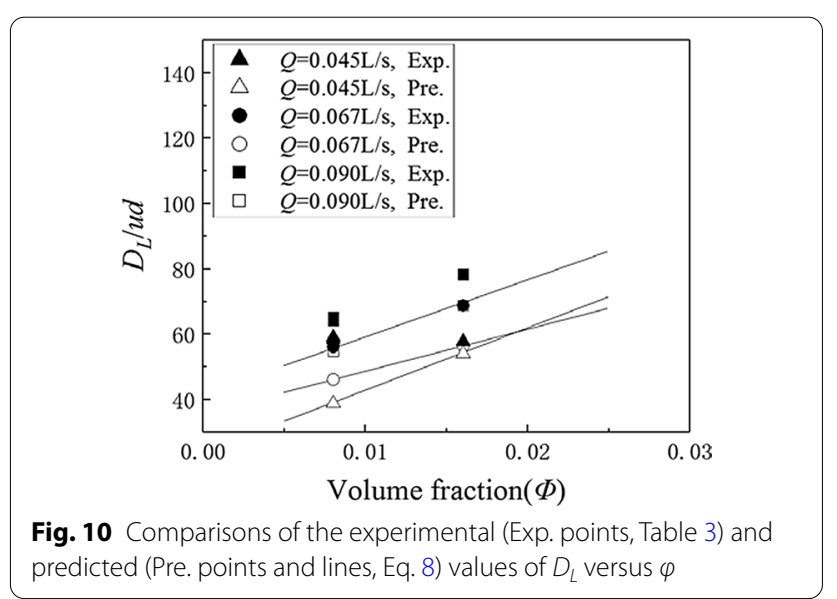

Cases $\mathrm{AA}, \mathrm{AB}$ and $\mathrm{AC}$ under all the inflow conditions. In Eq. (8), submergence of vegetation was considered by the relative water depth $\left(h_{v}{ }^{\prime} / h\right)$, which was equal to 1.0 for emergent rigid vegetation. In the case with flexible vegetation, flow velocity and solute transport were affected by vegetation bending, and also $h_{v}$ ' was not equal to $h$ due to the vegetation bending, resulting in the low accuracy in prediction of $D_{L}$.

As mentioned in the above sub-section, the effective submerged vegetation height was in the range of $11 \mathrm{~cm}-15 \mathrm{~cm}$ in the present experiments. The averaged value of effective submerged vegetation height $h_{v}{ }^{\prime \prime}=12 \mathrm{~cm}$ was used in Eq. (8) to predict $D_{L}$ affected by different vegetation densities (i.e., $\phi$ ). As shown in Fig. 11, the experimental and improved predictions of $D_{L}$ generally matched after considering the vegetation bending in terms of the effective submerged vegetation height, with the relative errors reduced to $5.5 \%, 10.4 \%$, and $10.1 \%$ in 


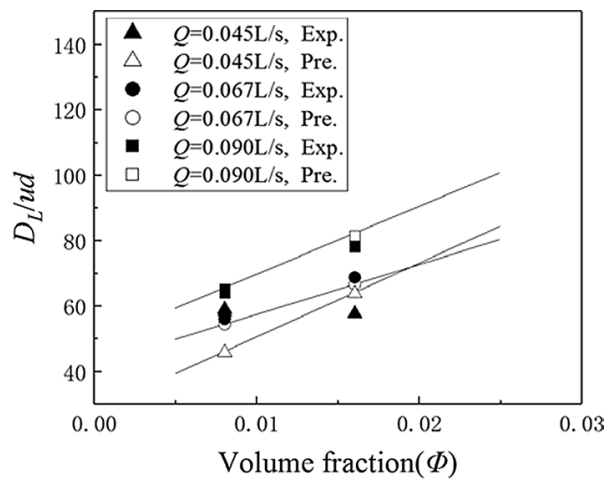

Fig. 11 Comparisons of the experimental (Exp. points, Table 3) and improved predicted (Pre. points and lines, Eq. 8) values of $D_{L}$ versus $\varphi$

Cases AA, AB and AC. According to Figs. 9 and 11, it was indicated that vegetation bending had a significant influence on $D_{y}$ and $D_{L}$ of solute transport in flows with flexible vegetation, and Eqs. (4) and (8) proposed for flows with rigid vegetation in our previous paper can be used to predict the $D_{y}$ and $D_{L}$ affected by flexible vegetation with a certain degree of accuracy by using the effective submerged vegetation height $h_{v}{ }^{\prime \prime}$ accounting for vegetation bending.

\section{Conclusions}

Laboratory experiments were carried out in this study to investigate the influence of flexible vegetation on solute transport, and the lateral and longitudinal diffusion coefficients were estimated based on the experimental measurements. Vegetation density had a significant effect on the mean velocity and solute distributions, while the vegetation arrangements (i.e., rectangular and staggered distributions) had less influence in the present experiments. In the vegetated flow, the Manning coefficient increased with vegetation density and decreased with inflow discharge. The solute concentrations were relatively lower in the case with denser vegetation due to the blocking effect. The vertical peak of the solute concentration moved from the injection height towards the bottom bed along the flow under all the cases. The values of vertical peak concentrations longitudinally decreased. Vegetation density had the opposite effect on $D_{y}$ and $D_{L} . D_{y}$ increased with vegetation density driven by the stem-scale turbulence, while $D_{L}$ decreased with vegetation density due to the reduction of flow velocity. Both $D_{y}$ and $D_{L}$ increased with the inflow discharge, which was positively related with turbulence and velocity. By using the effective submerged vegetation height accounting for vegetation bending, the methods (Eqs. 4 and 8) proposed for estimating $D_{y}$ and $D_{L}$ in flows with rigid vegetation in our previous paper were proved to be also appropriate for flows with flexible vegetation. And the predicted diffusion coefficients were close to those from experiments with the relative errors in the acceptable levels. These methods can be used to estimate the lateral and longitudinal diffusion coefficients of flows through both rigid and flexible, and emergent and submerged vegetation, if the effective submerged vegetation height was adopted. Results in this paper can enhance the simulation accuracy of solute transport diffusion affected by flexible vegetation, and provide basic data and technical support for wetland environmental protection and restoration, which has important theoretical significance and application value.

\section{Acknowledgements}

The authors thank anonymous reviewers, Associate Editor and Editor for their constructive comments.

\section{Authors' contributions}

$\mathrm{SL}$ and $\mathrm{HW}$ were responsible for conceptualization and methodology; $\mathrm{HL}$ designed the experiments; RLD, EN, and SL were involved in data processing; GZ and GM contributed to correction of the original manuscript. All authors reviewed and approved the final manuscript.

\section{Funding}

This work was sponsored by the Natural Science Foundation of China (42072281), International Cooperation Program of Shanghai Innovation Action Plan (20230742500) and Shanghai Peak Discipline Program for Civil Engineering School Tongji University (2019010207).

Availability of data and materials

The datasets used and/or analyzed during the current study are available from the corresponding author on reasonable request.

\section{Declarations}

Ethics approval and consent to participate

Not applicable.

Consent for publication

Not applicable.

\section{Competing interests}

The authors declare that they have no competing interests.

\section{Author details}

'Department of Hydraulic Engineering, Tongji University, Shanghai 200092, China. ${ }^{2}$ Key Laboratory of Yangtze River Water Environment, Ministry of Education, Tongji University, Shanghai 200092, China. ${ }^{3}$ Laboratory of Chemistry of Natural Systems, Baikal Institute of Nature Management of Siberian Branch of the Russian Academy of Sciences, 670047 Ulan-Ude, Republic of Buryatia, Russia. ${ }^{4}$ Department of Civil and Environmental Engineering, Old Dominion University, Norfolk, VA 23529, USA.

Received: 28 April 2021 Accepted: 27 June 2021

Published online: 05 July 2021

\section{References}

1. Azamathulla HM, Ahmad Z, Ghani AA (2013) An expert system for predicting Manning's roughness coefficient in open channels by using gene expression programming. Neural Comput Appl 23(5):1343-1349. https:// doi.org/10.1007/s00521-012-1078-z

2. Chen M, Lou S, Liu S, Ma G, Liu H, Zhong G, Zhang H (2020) Velocity and turbulence affected by submerged rigid vegetation under waves, 
currents and combined wave-current flows. Coastal Eng. https://doi.org/ 10.1016/j.coastaleng.2020.103727

3. Doncker L et al (2009) Determination of the Manning roughness coefficient influenced by vegetation in the river Aa and Biebrza river. Environ Fluid Mech 9(5):549-567. https://doi.org/10.1007/s10652-009-9149-0

4. Gerrard JH (1978) Wakes of cylindrical bluff bodies at low Reynoldsnumber. Philos Trans R Soc A-Math Phys Eng Sci 288(1354):351-382

5. Hamidifar H, Omid MH, Keshavarzi A (2015) Longitudinal dispersion in waterways with vegetated floodplain. Ecol Eng 84:398-407. https://doi. org/10.1016/j.ecoleng.2015.09.048

6. Hui EQ, Cao GJ, Jiang CB, Zhu ZD (2010) Longitudinal dispersion of pollutants in flow through natural vegetation. 2010 4th International Conference on Bioinformatics and Biomedical Engineering (ICBBE 2010), IEEE, New York, USA. https://doi.org/10.1109/ICBBE.2010.5517006

7. Jamali M, Davari H, Shoaei F (2019) Lateral dispersion in deflected emergent aquatic canopies. Environ Fluid Mech 19(4):833-850. https://doi.org/ 10.1007/s10652-019-09666-0

8. Liu C, Shan Y, Liu X, Yang K, Liao H (2016) The effect of floodplain grass on the flow characteristics of meandering compound channels. J Hydrol 542:1-17. https://doi.org/10.1016/j.jhydrol.2016.07.037

9. Lou S, Chen M, Ma G, Liu S, Zhong G (2019) Modelling of stem-scale turbulence and sediment suspension in vegetated flow. J Hydraul Res. https://doi.org/10.1080/00221686.2020.1780491

10. Lou S, Liu H, Liu S, Chen M, Zhong G (2020) Longitudinal and lateral diffusion of solute transport affected by rigid vegetation. Environ Sci Eur. https://doi.org/10.1186/s12302-020-00315-8

11. Lu J, Dai HC (2016) Effect of submerged vegetation on solute transport in an open channel using large eddy simulation. Adv Water Res 97:87-99. https://doi.org/10.1016/j.advwatres.2016.09.003

12. Lu J, Dai HC (2018) Numerical modeling of pollution transport in flexible vegetation. Appl Math Model 64:93-105

13. Nepf HM (2004) Vegetated flow dynamics. Coastal Estuarine Studies. 59:137-163. https://doi.org/10.1029/CE059p0137

14. Nepf HM, Mugnier CG, Zavistoski RA (1997) The effects of vegetation on longitudinal dispersion. Estuarine Coastal Shelf Sci 44(6):675-684. https:// doi.org/10.1006/ecss.1996.0169

15. Nepf HM, Sullivan JA, Zavistoski RA (1997) A model for diffusion within emergent vegetation. Limnol Oceanography. 42(8):1735-1745. https:// doi.org/10.4319/lo.1997.42.8.1735

16. Nepf HM (1999) Drag, turbulence, and diffusion in flow through emergent vegetation. Water Resources Res 35(2):1985-1986. https://doi.org/ 10.1029/1998WR900069
17. Nepf HM, Ghisalberti M (2008) Flow and transport in channels with submerged vegetation. Acta Geophys 56(3):753-777

18. Okamoto T, Nezu I (2010) Large eddy simulation of 3-D flow structure and mass transport in open-channel flows with submerged vegetations. J Hydro-environ Res 4(3):185-197

19. Pannone M (2014) Predictability of tracer dilution in large open channe flows: analytical solution for the coefficient of variation of the depthaveraged concentration. Water Resources Res 50(3):2617-2635. https:// doi.org/10.1002/2013WR013986

20. Serra T, Fernando HJS, Rodriuez RV (2004) Effects of emergent on lateral diffusion in wetlands. Water Res 38(1):139-147. https://doi.org/10.1016/j. watres.2003.09.009

21. Stelzer RS, Likens GE (2006) Effects of sampling frequency on estimates of dissolved silica export by streams: the role of hydrological variability and concentration-discharge relationships. Water Resources Res. https://doi. org/10.1029/2005WR004615

22. Stone MC, Chen LI, Mckay SK et al (2013) Bending of submerged woody riparian vegetation as a function of hydraulic flow conditions. River Res Appl 29(2):195-205. https://doi.org/10.1002/rra.1592

23. Tsujimoto T (1999) Fluvial processes in streams with vegetation. J Hydraul Res 37(6):789-803

24. Wen J, Guo J, Zai S et al (2008) Two-station straight-line analytical method for data analysis of river water mass tracer test. J Hydraulic Eng. 39(5):618622. https://doi.org/10.3321/j.issn:0559-9350.2008.05.016 (In Chinese)

25. White FM (2005) Viscous fluid flow, vol 20. McGraw-Hill, New York, pp $548-550$

26. White B, Nepf HM (2003) Scalar transport in random cylinder arrays at moderate Reynolds number. J Fluid Mech 487:43-79. https://doi.org/10 1017/S0022112003004579

27. Yerdelen C, Mertsoy M, Tayfur G (2015) Investigation of Manning coefficient caused by rigid body plants. Teknik Dergi 26(2):7055-7076

28. Zebardast S, Tabatabaei S, Abbasi F, Heidarpour M (2020) Solute mixing in a permeable non-rectangular channel. Int J Sedim Res 35(2):134-145. https://doi.org/10.1016/j.ijsrc.2019.10.007

29. Zheng P, Guo J. (1999) Linear regression method for determining lateral diffusion coefficient of rivers. Water Resources Power. 17(3): 17-19. (In Chinese). CNKI: SUN:SDNY.0.1999-03-004

\section{Publisher's Note}

Springer Nature remains neutral with regard to jurisdictional claims in published maps and institutional affiliations.

\section{Submit your manuscript to a SpringerOpen ${ }^{\circ}$ journal and benefit from:}

- Convenient online submission

- Rigorous peer review

- Open access: articles freely available online

- High visibility within the field

Retaining the copyright to your article

Submit your next manuscript at $\boldsymbol{\nabla}$ springeropen.com 